\title{
INTERthesis
}

DOUTORADO INTERDISCIPLINAR EM CIÊNCIAS HUMANAS - UFSC - FLORIANÓPOLIS - SC - BRASIL

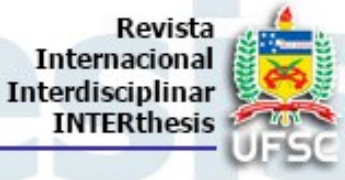

\section{UMA ANTROPOLOGIA DO “FLUXO”: REFLEXÕES SOBRE DEPENDÊNCIA NO CONTEXTO DO CRACK}

\section{Resumo:}

Ygor Diego Delgado Alves ${ }^{1}$

Pedro Paulo Gomes Pereira ${ }^{2}$

O conceito biomédico de dependência não consegue dar conta da atração exercida pelas cenas de uso de crack que vai muito além da necessidade de se consumir uma droga para aliviar a fissura. Uma antropologia do "fluxo", como são chamados os movimentos e percursos em torno do consumo do crack, permitiu refletir sobre o porquê da existência de cracolândias e questionar certas dimensões da chamada dependência química. Prazer e sofrimento passam a ser considerados em sua dimensão social: a satisfação proporcionada em desfrutar da companhia de outros usuários e o constrangimento provocado pelo estigma em torno da droga. A conexão com os parças e a relações estabelecidas nas ruas possibilitam a fruição dos efeitos desejados da substância e ensinam modos de viver e perceber a cidade.

Palavras-chave: Etnografia. Crack. Dependência. Cracolândia. Fluxo

\section{ANTHROPOLOGY OF "THE FLOW": REFLECTIONS ON ADDICTION IN THE CONTEXT OF CRACK COCAINE}

\begin{abstract}
:
The biomedical concept of addiction cannot handle the attraction of the crack consuming scenes that goes far beyond the need to use a drug to relieve the craving. An anthropology of the "flow" - as the movements and trajectories that surround the consumption of crack cocaine are called - allowed me to reflect on the motivations for the existence of cracolândias (urban zones dominated by the sale and use of crack cocaine), and to question certain dimensions of so-called drug addiction. Over the course the study, I consider pleasure and suffering in terms of their social dimensions, such as the satisfaction of sharing in the company of other crack users, or the shame that the drug's stigma provokes. The connections between parças (roughly, "homies") and the relationships established on the street allow the substance's desired effects to come to fruition while also teaching users different modes of living in and perceiving the city.
\end{abstract}

Keywords: Ethnography. Crack Cocaine. Addiction. Cracolândia. Flow.

\footnotetext{
1 Doutor em Antropologia pela Universidade Federal da Bahia. Pós-doutorando em Saúde Coletiva pela Universidade Federal de São Paulo, São Paulo, SP, Brasil. E-mail: antropologiaygor@yahoo.com.br

2 Livre Docente pela Universidade Federal de São Paulo. Pós-Doutorado na Universidade de Barcelona, Barcelona, Espanha. Professor Associado da Universidade Federal de São Paulo. Professor do Programa de Pós-Graduação em Saúde Coletiva da Universidade Federal de São Paulo, São Paulo, SP, Brasil. E-mail: pedropaulopereira@hotmail.com
} 


\section{UNA ANTROPOLOGÍA DEL "FLUJO": REFLEXIONES SOBRE DEPENDENCIA EN EL CONTEXTO DEL CRACK}

\section{Resumen:}

El concepto biomédico de dependencia no puede dar cuenta de la atracción ejercida por las escenas de uso de crack que va mucho más allá de la necesidad de consumir una droga para aliviar la fisura. Una antropología del "flujo", como se llaman los movimientos y recorridos alrededor del consumo del crack, permitió reflexionar sobre el porqué de la existencia de cracolandias y cuestionar ciertas dimensiones de la llamada dependencia química. El placer y el sufrimiento pasan a ser considerados en su dimensión social: la satisfacción proporcionada en disfrutar de la compañía de otros usuarios y la vergüenza provocada por el estigma en torno a la droga. La conexión con los camaradas y las relaciones establecidas en las calles posibilitan la fruición de los efectos deseados de la sustancia y enseñan modos de vivir y percibir la ciudad.

Palabras clave: Etnografía. Crack. Dependencia. Cracolândia. Flujo

\section{INTRODUÇÃO}

Este artigo trata da cracolândia paulistana. Sua existência vem desafiando o esforço interpretativo da grande mídia e da academia por mais de vinte anos, sendo objeto de intervenções estatais e da sociedade civil que vão desde a violência mais desenfreada até políticas inclusivas de reconhecimento internacional. Porém, apesar de todo o trabalho realizado pelos(as) pesquisadores(as) até o momento, que servem de base para nossa análise e com os quais iremos debater. Acreditamos, pelo tipo de inserção que empreendemos no campo, uma etnografia por quase seis anos com a possibilidade de frequentar as rodas de consumo de crack nos mais variados horários do dia e épocas do ano, poder oferecer um ponto de vista que nos permita elucidar considerações consistentes sobre o porquê da existência e enorme resiliência da Cracolândia. Assim como, lançar uma luz sobre a existência de cenas abertas de uso do crack.

Localizada na região central da cidade de São Paulo, a Cracolândia, é uma imensa cena de uso de crack que chegou a possuir um "fluxo" 3 de mil e quinhentos frequentadores diários (PREFEITURA DO MUNICÍPIO DE SÃO PAULO, 2015). O local foi objeto de pesquisas etnográficas, referências sobre as quais fundamentamos nosso raciocínio, que destacaram os mais variados enfoques, tais como: (1) as relações entre o Estado, o legal e o ilegal (ADORNO et al., 2013;

\footnotetext{
${ }^{3}$ De modo geral, o termo refere-se aos movimentos e percursos em torno do consumo da droga
} (Alves, 2015). 
SILVA, e ADORNO, 2013; RUI, 2012b), (2) a cobertura midiática das ações policiais (RUI, 2013), (3) a territorialidade e suas conexões com a cidade (FRÚGOLI JÚNIOR, CAVALCANTI, 2013; RUI, 2014), (4) as ações de entidades sociais (SPAGGIARI, RODRIGUES, e FONSECA, 2012), (5) as estratégias de autocontrole e autocuidado (ADORNO, et al. 2014; RAUP, e ADORNO, 2015), (6) as práticas de lazer e resistência (ADERALDO, e FAZZIONI, 2012; CALIL, 2016), (7) as relações entre saúde e ambiente (COSTA, 2015).

Nos anos de 2013 e 2014, realizamos uma etnografia na região central de São Paulo por meio de observação participante, de entrevistas e de acompanhamento da vida cotidiana dos usuários de crack. Dois anos após, em 2016, voltamos a campo, agora, no entanto, numa pesquisa sobre o Programa de Braços Abertos (doravante DBA). ${ }^{4}$ A experiência etnográfica demonstrou que a atração exercida por esses locais não só se limita à droga, mas também que essa associação exclusiva e imediata com o crack ignora múltiplos aspectos do contexto de uso.

Ao refletir sobre essas questões, procuraremos pensar em uma antropologia do "fluxo", sempre com o intuito de respeitar as informações dos interlocutores, sem cortá-las com explicações que Ihes sejam extrínsecas. Tal movimento leva a refletir sobre o porquê da existência de cracolândias e a questionar certas dimensões da chamada dependência química (ARAÚJO, et al., 2008).

\section{O "FLUXO" E A CONEXÃO COM OS PARES}

A atração exercida pelo "fluxo" pode ser creditada à possibilidade ali existente de os indivíduos se relacionarem diretamente, conversando em pequenos grupos e movimentando-se entre eles (ALVES, 2015). Além da Cracolândia, espalham-se pela cidade muitas "biqueiras", locais de venda e, por vezes, também de uso, com suas diversas e movimentadas rodas de crack, que se caracterizam pelo consumo coletivo de substâncias psicoativas (MERCANTE, 2015). Esses agrupamentos de pessoas, materiais e substâncias, em especial na Cracolândia, vêm chamando a atenção dos governos, dos especialistas e da mídia, tornando-se um dos problemas sociais mais debatidos nas últimas duas décadas (FERES

\footnotetext{
${ }^{4}$ Refiro-me à pesquisa "O uso do crack como problema de saúde pública e o Programa de Braços Abertos" (Fapesp, 15/19667-0), sob a responsabilidade do Prof. Dr. Pedro Paulo Gomes Pereira.
} 
JÚNIOR, 2012). Nas páginas dos jornais, os "craqueiros"5 são retratados como inumanos e como um mal a ser extirpado (CHAGAS, e SEEGER, 2013). Nos discursos dos especialistas surgem termos como risco, vulnerabilidade e precariedade (Jorge, et al., 2013). Os locais de uso do crack são percebidos como espaços vinculados exclusivamente ao consumo da substância, representados por imagens estigmatizantes associadas à dependência física (ROMANINI, e ROSO, 2014) e à utilização de estimulantes em binge, definida por um padrão de consumo crônico. Nesse período, o usuário mantém-se insone e sem alimentação, o que resulta em total exaustão e na falta de fundos para manter o consumo da droga (CHAVES, et al., 2011). O termo binge, no caso do álcool, também diz respeito ao uso episódico pesado com um intervalo curtíssimo de tempo entre uma dose e outra. Mas pouco se fala sobre o que move essas pessoas para a formação de conjuntos tão sui generis e sobre o que os atrai para o "fluxo".

Importante ressaltar, com Rui (2014), que ao falarmos de usuários de crack não descartamos o processo histórico pelo qual o desvio individual e a dependência se tornaram negócios de saúde pública. Neste percurso a questão do abuso de drogas deixou de ser pensada como um problema prioritariamente de segurança, como ocorria desde a cruzada contra a "vadiagem", marcada por concepções racistas (LEMÕES, 2017), permitindo que as políticas se inscrevessem nos territórios sob outra ótica, a da saúde. As pessoas que fazem uso do crack e vivem nas ruas, particularmente na Cracolândia, são, portanto, também produto de intervenções do Estado como alvos de políticas públicas direcionadas e fortemente marcadas pela violência, formas de classificação e categorias de acusação. Não apenas frutos de decisões, trajetórias ou dramas individuais, por mais significativos que sejam.

Vemos então que a existência do "fluxo" decorre, além das contingências impostas pela ação estatal, do fato de o crack ser fumado, na maioria das vezes, em uma roda e não de modo solitário. Fumar sozinho requer que o usuário tenha todo o "maquinário"6 à sua disposição, provocando assim o afastamento do circuito da

\footnotetext{
${ }^{5}$ Os termos Cracolândia e "craqueiro" são pejorativos. Cracolândia é usado por meus interlocutores, o que não acontece com craqueiro. Não percebi em todo trabalho de campo um termo que pudesse denotar uma referência positiva ao usuário de crack, apenas expressões genéricas para dizer que tal pessoa "é do crack", "é do fluxo" ou "é cria da casa". Já o termo "maloqueiro" pode ser usado circunstancialmente de modo elogioso.

${ }^{6} \mathrm{O}$ mesmo que parafernália.
} 
"treta"7 e da "sintonia"8 (ALVES, 2017). Alija, parafraseando Timothy Leary (1999 [1990]), um aspecto fundamental do prazer de fumar: aquela sensação gostosa de cumplicidade entre os que compartilham a mesma pedra. Se não se considerar essa dimensão social do prazer, a compreensão das motivações do usuário fica restrita apenas ao uso do crack ou - mais errôneo ainda - ao alívio da fissura. ${ }^{9}$

No decorrer da etnografia, percebemos que, nas cenas de uso, se escolhiam múltiplos ambientes para melhor manipular os efeitos da "brisa". ${ }^{10}$ Isso provocava, segundo as diversas oportunidades abertas pelos variados estados corporais, uma interação com locais distintos e possíveis "parças". ${ }^{11}$ A experiência etnográfica demonstrou que os padrões de uso, mesmo na rua, passam por diferentes gradações na história de cada um e dependem dos imponderáveis do cotidiano, variando do padrão controlado (OLIVEIRA, e NAPPO, 2008) ao descontrolado ou , como disseram reiteradas vezes nossos interlocutores, de "se deixar levar". Este padrão se assemelha ao nível de engajamento com o crack do noia, ligado às condições de abjeção e central na pesquisa de Rui (2014). A "brisa" depende do ambiente de consumo, podendo variar desde sensações agradáveis e prazerosas, acompanhadas de disposição para as mais diversas atividades - sejam elas voltadas ao trabalho ou à sociabilidade - até a "paranoia", na qual prevalecem movimentos repetitivos, a preocupação e o desprazer.

A possibilidade do uso controlado de drogas foi observada nos primórdios das pesquisas antropológicas sobre o consumo de substâncias, particularmente da maconha, como presente em Becker (2008 [1963]). Caso supere bem, em sua carreira de usuário de maconha, os desafios quanto ao fornecimento da droga, ao sigilo quanto a seu uso e possa livrar-se dos impedimentos morais a constrangê-lo, o maconheiro poderá finalmente se tornar um usuário controlado. Isto, de modo algum, irá levá-lo ao comportamento estereotipado de estar usando o tempo todo, muito pelo contrário [...] "Seu uso é planejado; considera-o apropriado em certas ocasiões, não em outras". (BECKER, 2008, p. 84) Ele assegura para si mesmo

\footnotetext{
${ }^{7}$ A "treta" é a troca generalizada de bens e serviços em torno do consumo do crack. Água, vestuário, cigarros, bebida alcoólica, itens da parafernália de uso, assim como serviços do tipo buscar água e limpar o local, são constantemente trocados dentro e fora dos barracos.

8 "Sintonia" é o termo utilizado pelos interlocutores para designar o sentimento agradável de empatia entre os usuários de crack.

${ }^{9}$ Para uma abordagem detalhada sobre a fissura, ver Chaves, et al. (2011)

10 "Brisa" corresponde ao conjunto de sensações de certa forma idiossincráticas experimentadas a partir do uso do crack. Pode também dizer respeito ao comportamento de quem fumou.

11 "Parças" são colegas, no mais das vezes usuários de crack.
} 
possuir o controle sobre seu uso da droga e isto funciona como símbolo dele desempenhar uma prática inócua. Portanto, não é escravo porque planeja e segue seu plano quanto à quantidade, frequência e oportunidade, com períodos sem o uso da substância psicoativa. Esta ideia foi fundamental para surgir uma nova visão a respeito de se fumar maconha, comportamento, até então, quase que exclusivamente desqualificante. Também um exemplo de como categorias de definição e classificação de sujeitos podem produzir a realidade social.

O uso de drogas também impõe a necessidade de aproximação das fontes de fornecimento, o sigilo e a discrição diante dos não usuários e das pessoas importantes, como as do círculo familiar. $O$ usuário deve mostrar destreza em manejar os efeitos da droga na presença dos não usuários. A companhia dos "parças" é também valorizada por permitir uma fruição mais agradável desses efeitos. $O$ agrupamento dos usuários de crack pode também se constituir em uma resposta às dificuldades de se manterem ligados à rede social familiar (MOURA, SILVA, e NOTO, 2009) e mesmo uma contraposição à morte social (PINHEIRO, e ANJOS, 2014) a que são condenados pelo estigma (GOFFMAN, 1975 [1963]) decorrente de seu hábito.

Essa conexão com os pares no local de consumo do crack e a identificação com um modo de vida esboçam os primeiros contornos dos componentes sociais presentes na manutenção do uso e possibilitam ir mais além do que se convencionou designar como "dependência química". Ser um usuário de crack é estar emaranhado aos pares nos locais de uso, compartilhar certa percepção e vivência da cidade. Usar crack permite ingressar no setting do "fluxo", o território psicotrópico (FERNANDES, e PINTO, 2004) de uso e comércio do crack, assim como ter acesso à circulação dos materiais que compõem a parafernália de uso por meio da "treta". Pensar nessas dimensões pode ajudar a entender o porquê das cracolândias.

\section{POR QUE EXISTEM CRACOLÂNDIAS?}

Quando iniciamos as pesquisas sobre o consumo do crack em São Paulo, a questão que de imediato nos surgiu foi o porquê da formação de tão extensas aglomerações humanas em torno dessa prática, ao contrário de outras drogas, como a maconha e mesmo a cocaína cheirada ou injetada. A Cracolândia paulistana 
parecia guardar maior semelhança com as raves e festivais da cerveja, outras grandes concentrações humanas de certa forma centradas no consumo de substâncias. Era, portanto, semelhante a uma grande festa ininterrupta com duas décadas de duração que insistia a desafiar nossa capacidade de interpretação.

Uma autora que se debruçou sobre esta dificuldade interpretativa foi Rui (2014). Em Nas tramas do crack: etnografia da abjeção, a antropóloga valoriza a etnografia ao mostrar a sociabilidade no contexto de uso desta droga. A partir das histórias dos interlocutores descreve modos de aquisição da substância, técnicas de uso e de gestão corporal. Assim pode se contrapor ao discurso homogeneizador presente na mídia; e propor um corpo como lugar discursivo mergulhado em relações de poder, perceptíveis, por exemplo, nas ações policiais. Desencadeadas sobre certa territorialidade em que também estão presentes uma rede de relações de cuidado e proteção, assim como de conflitos e desconfianças marcadas pela presença do crime organizado. A Cracolândia produz efeitos no imaginário social e na realidade urbana. A cena de uso gera intervenções de entes públicos e privados que podem se materializar em forma de incriminação e repressão.

A violência presente na guerra às drogas dá o pano de fundo para o consumo da droga por toda carreira do usuário (BECKER, 2008). O uso inicial do crack pode se assemelhar ao de drogas consideradas muito menos danosas, como a maconha. ${ }^{12} \mathrm{O}$ neófito não sente, necessariamente, os efeitos logo após a primeira experiência, o que só ocorre com a colaboração, a confiança e o incentivo de um usuário mais experimentado para aprender a apreciar a ação da droga. Isso é possível a partir da superação das imagens negativas sobre o crack adquiridas anteriormente, fora do grupo de usuários. Para permanecer como usuário, particularmente na Cracolândia, se faz necessário enfrentar um cotidiano de violência nas suas mais variadas formas, desde a agressão aberta por parte da polícia até humilhações cotidianas um pouco mais sutis.

A lavagem diária das calçadas da Cracolândia, ao cair da tarde, constrangia e trazia instabilidade às acomodações, em uma situação de lumpen abuse, violência praticada contra pessoas muito dificilmente integráveis à força de trabalho (BOURGOIS; SCHONBERG, 2009). Por isso, percebemos ali, no início de nossa pesquisa de campo no primeiro bimestre do ano de 2013, mais cenas de uso

12 O livro Por que não dancei, de Esmeralda Ortiz (2001), traz uma rica descrição da iniciação no uso do crack e suas dificuldades. 
descoberto em comparação a outros locais de "fluxo". A Cracolândia era um espaço de uso e comércio intenso. Compreendia, no começo da etnografia, parte da rua do Triunfo e rua dos Gusmões, assim como o quadrilátero entre a Alameda Glete, a Avenida Rio Branco, a Avenida Duque de Caxias e a Alameda Cleveland. Neste espaço, entre a Praça Princesa Isabel e a Estação Júlio Prestes estão o Largo Coração de Jesus e a Praça Júlio Prestes.

A chamada Cracolândia está entre duas importantes áreas de práticas ilícitas na história recente de São Paulo: a antiga zona de prostituição do bairro do Bom Retiro e a Boca do Lixo. Até os anos 1930, a prostituição limitava-se à rua Timbiras, no limite da Boca do Lixo, do lado oposto à atual Cracolândia; posteriormente, essa área de meretrício foi deslocada pelo poder público para a rua Aimorés, no Bom Retiro, lá permanecendo até as vésperas das comemorações dos 400 anos da cidade, em 1954. Sua dissolução provocou o deslocamento de prostitutas, cafetões, punguistas e "toxicômanos" para a famosa Boca do Lixo. (JOANIDES, 1978, p. 15). Fica claro o quanto esse espaço é mutável. Contudo, há muito viceja na região uma tradição de práticas delituosas e passíveis de estigmatização. Até a implementação do Programa DBA, apenas a rua dos Gusmões mantinha, fora das proximidades da esquina da rua Helvétia com Dino Bueno e Cleveland, onde atualmente se localiza o "fluxo", o comércio de crack em pleno movimento, tanto durante o dia quanto no período noturno. Também durante a noite, a rua do Triunfo era ocupada por usuários nas proximidades do Largo General Osório ${ }^{13}$, sendo que neste local se formava um "fluxo". Estes dados históricos e geográficos sobre a região certamente possuem valor heurístico, porém, a prática etnográfica nos colocou na cena de uso e, com isso, trouxe a possibilidade de entrar em contato com os personagens do lugar. Destes tantos interlocutores, alguns nos auxiliarão a descortinar as razões daquele espaço.

Mariano, um frequentador da Cracolândia, 40 anos, informou que, além das ruas do bairro da Luz, também reside, parte do tempo, na casa de sua avó há mais de dez anos. Contou que na rua podia usar crack, o que era vedado em sua residência. Voltava para casa da avó regularmente, porém os períodos na Cracolândia eram de duração superior. Como os outros frequentadores do local, ele

\footnotetext{
${ }^{13}$ A região é repleta de "biqueiras" e hotéis com quartos disponíveis para curtos períodos e tolerantes com o uso de crack, além de albergues privados com preços de $R \$ 7,00$ a $R \$ 10,00$ sendo o leito em quarto compartilhado com direito a armário, banho e café da manhã.
} 
se dedicava com afinco à "treta" e possuía seus "parças", inclusive um primo denominado Corintiano, que aparentava ter 35 anos. Também residente na região da Luz há pelo menos uma década, ele era casado com uma usuária que tive a oportunidade de conhecer. Voltaremos à história de Corintiano mais à frente.

Outro caso semelhante é o de Carazinho, também na faixa dos 40 anos, o primeiro usuário de crack com quem tivemos contato na Cracolândia. Como muitos outros membros da população flutuante local, portava uma mochila; nela carregava seus instrumentos de trabalho como pintor de paredes com compressor de tinta. Após receber o pagamento por algum serviço, dirigia-se à Cracolândia para consumir crack e rever os "parças". Quando terminava o dinheiro, retornava ao trabalho abandonado ou procurava uma nova ocupação temporária. A mochila nas costas e sua habilidade como pintor Ihe permitiam um modo de vida desprendido de maiores vínculos externos aos diversos grupos de usuários que frequentava. Assim como Mariano, Carazinho possuía residência fora da Cracolândia, porém era um local para onde procurava se dirigir o mínimo possível por ter problemas de relacionamento com seus parentes. Ambos declararam que esses conflitos eram decorrentes do uso de crack.

Tanto para Carazinho quanto para Mariano, estar na Cracolândia era a maneira de se livrar da desaprovação familiar ao hábito de consumir crack. É possível que eles não conseguissem controlar os efeitos da pedra a ponto de poder utilizá-la junto ao círculo. Mas não era apenas isso o que os afastava desse convívio. A experiência etnográfica possibilitou-nos perceber como as sensações prazerosas do crack dependem da "sintonia" entre usuários ${ }^{14}$. Seu consumo pode se prolongar por dias ininterruptos, padrão binge. Com isso, fica mais difícil sua fruição nas proximidades de membros da família e favorece, portanto, a aproximação entre os usuários. Para fumar crack é melhor estar na companhia uns dos outros usuários; para estar na companhia deles e não comprometer a "sintonia", é necessário fumar crack.

A Cracolândia e outras cenas de uso são locais onde o usuário fica livre da companhia julgadora dos outsiders ${ }^{15}$ (familiares, amigos, colegas de trabalho ou de

\footnotetext{
14 Como observou Howard Becker (2008 [1963], 76-87), para poder desfrutar dos efeitos prazerosos da maconha, faz-se necessária tanto a companhia de outros maconheiros quanto a distância de não usuários que obrigam o maconheiro a dispender um grande esforço em disfarçar os efeitos da droga ao invés de aproveitá-los.

${ }^{15}$ Não usuários da droga. Veja detalhadamente em Becker (2008 [1963], 69-87).
} 
escola) e, ao mesmo tempo, se aproveita da companhia de "parças" com quem se pode viver em "sintonia". Também é possível ficar próximo às fontes de fornecimento e à circulação da pedra através da "treta". Além disso, existem dificuldades de ordens diversas para usar drogas na presença de pessoas valorizadas. Ser descoberto é correr o risco da desqualificação decorrente do estigma criado em torno do uso e do usuário de drogas ilícitas. É arriscar-se a sofrer sanções legais que podem chegar até a prisão. Ser um desviante puro (Becker, 2008 [1963], 31-36), aquele que demonstra possuir um comportamento infrator e é percebido como tal enfim, "ser do crack" -, expõe a pessoa a uma grande probabilidade de ser tachada de irresponsável, descontrolada ou mesmo louca.

Mariano narrou seu relacionamento problemático com a avó e a "profecia" feita por seu avô quando ele era menino e morador de uma cidade do sertão nordestino. Seu avô disse que ele "não daria em nada", ou seja, não seria alguém na vida. Para a família, as prisões de Mariano por roubo de veículo e outros crimes vieram confirmar a predição do avô. Esse desgaste acabou por colocá-lo em situação semelhante à de rua, na qual se consideram seus longos períodos nas calçadas da Cracolândia. Assim, as histórias dos usuários de crack, moradores de rua, acabam por se entrelaçar com as dos "parças" que percorrem caminhos semelhantes.

A carreira do usuário ${ }^{16}$ se torna um caminho de progressiva exclusão da sociedade abrangente e de inclusão em um grupo divergente (VELHO, 2013) com todo o impacto que isso exerce sobre a concepção da pessoa sobre si mesma. Ela passa a assumir que "sou da marginalia, sou do crack", ${ }^{17}$ adotando uma identidade desviante (BECKER, 2008 [1963]; TINOCO, 1999) advinda de um sentimento de destino comum aos usuários de drogas.

A maior ou a menor necessidade de permanecer na cena de uso varia desde a capacidade de manejar os sintomas associados e sua relação com a manutenção do sigilo, até a adoção - e isto é de fundamental importância - de novas formas de participação social que reduzem quase totalmente as interações com não usuários. O consumo regular só poderá permanecer caso se consiga lidar com os riscos de

16 O conceito de carreira foi trazido por Becker (2008 [1963]) da literatura de administração de empresas, particularmente da administração de recursos humanos. Assim, a experiência com o uso de uma substância é obtida através do tempo e não apenas pontualmente, porque para se tornar um maconheiro "de sucesso" -aquele capaz de usá-la por prazer - se faz necessário insistir no uso, mesmo apesar de uma possível má experiência.

${ }^{17}$ Afirmação feita por um usuário experiente para se referir aos de aparência mais comprometida. 
ser descoberto com a droga e de ser capaz de camuflar seus efeitos na presença de outsiders. Se conseguir controlar de forma convincente os sintomas aparentes capazes de denunciar o hábito a não usuários de quem se deseja manter o sigilo -, poderá continuar a manter contato com esses não usuários. Porém, quanto maior a dificuldade em manejar as marcas corporais (voz rouca, boca seca, dedos queimados e/ou enegrecidos) mais o usuário será induzido a permanecer maior tempo com o grupo divergente.

Usar crack e conviver com parentes é ainda mais que uma questão de manejo de sintomas, é também uma forma de lidar com outras materialidades, como é o caso da fumaça (FIORE, 2013). Assim como quem usa maconha, o usuário de crack se vê às voltas com as dificuldades de ser denunciado pelo aroma característico da sublimação da pedra de crack, pela luminosidade emanada do Bic (termo usado para isqueiro de qualquer marca), pela fumaça e luz do próprio cigarro e pelo cheiro que impregna as vestimentas e os cabelos. Administrar os sintomas na presença do "Zé Povinho"18 pode consumir uma parcela importante do prazer em utilizar a droga. Portanto, os usuários não fumam em suas casas; se o fazem, procuram ser discretos.

Antes de se deparar com essas questões, para experimentar crack o futuro usuário precisa vencer o medo inicial decorrente da observação de usuários decadentes ou de preconceitos advindos da sociedade mais ampla. Ao aprender a usar a droga e a se enturmar com outros pares, ele passa a desenvolver uma visão alternativa sobre o uso do crack, diferente daquela assimilada pelo "Zé Povinho".

Em meio à comemoração de uma festa junina, realizada na Cracolândia, no ano de 2013, conversei com Corintiano, primo de Mariano, no meio da rua durante cerca de duas horas. Às vezes, nos dirigíamos à calçada para que meu interlocutor pudesse fazer uso das pedras em seu poder com o mínimo de "radiação". ${ }^{19}$ Com frequência, ele era abordado por diversos usuários que the pediam para serem "favorecidos" 20 e the propunham as mais diversas "tretas". Apesar de se irritar com tal assédio, Corintiano participava da "treta", desde que se mostrasse vantajosa. Quando compramos um interessante cachimbo feito de lâmpada, ele começou a tecer algumas considerações sobre a visão negativa que os não usuários possuíam

\footnotetext{
18 Termo pejorativo utilizado para se referir aos não usuários de crack.

19 Barulho, confusão e desavenças trazidas para o ambiente onde se está consumindo crack, o inverso da "sintonia".

${ }^{20}$ Favorecer, nesse contexto, é o ato de fornecer crack e itens da parafernália a alguém.
} 
deles: "Eles acham que nós somos lixo, né? Se eles veem um cara caído na rua, ninguém faz nada. Se eu encontrar um cara caído na rua, eu vou ajudar, não vou tratar ele como lixo. [...] Nós somos a Nova Jerusalém"21.

Corintiano possui certa autoimagem positiva e mesmo superior à do "Zé Povinho", pois ele se vê como altruísta e solidário. Ao lhe pedirmos de volta o cachimbo que havíamos comprado, ele me declarou: "Eu ia te devolver, porque eu sou homem". Ser alguém de índole honesta é, portanto, um valor entre os usuários de crack tanto quanto na sociedade abrangente. Ser honesto foi também um motivo de orgulho para Mariano. Ao conversarmos com ele a respeito de "gente que pilantrava" 22 e era punida pelos "irmãos", ${ }^{23}$ ele fez questão de nos contar a respeito de casos em que objetos de valor Ihe foram confiados e da maneira correta como se comportou. Portanto, no "fluxo", é possível surgir uma autoconcepção como seguidor ordeiro da disciplina imposta pelos "irmãos" e também como pessoa bondosa, altruísta. Enfim, uma "Nova Jerusalém".

Pudemos observar outras formas de autoimagem positiva na figura de nosso interlocutor Zezé, artista plástico carioca de 40 anos de idade - dez deles como morador de rua -, que se sente orgulhoso por deixar seu barraco arrumado, o melhor da "biqueira" a céu aberto, por "brisar na libido", por ter namorada, pela atração que exerce sobre algumas mulheres jovens e bonitas e, principalmente, por não ser um "parasita". Zezé estabelece a diferença entre o usuário consciente e que ele considera como o "dependente químico": o primeiro é capaz de dominar sua vontade e cumprir seus afazeres, ao contrário do dependente. Ele se vê, portanto, como um usuário de crack capaz de "usar sem ser usado". Essa máxima, que denota a valorização do uso controlado, é constantemente ouvida na Cracolândia. Em Salvador (BA), a antropóloga Luana Malheiros (2012; 2013) observou algo semelhante acerca do distanciamento entre usuários e "sacizeiros". Este último é caracterizado pelo descontrole no uso de crack, ao contrário do usuário. Essas formulações sugerem, portanto, uma forma diferente de compreender a dependência.

\footnotetext{
${ }^{21}$ Nova Jerusalém é o nome dado à cidade que Deus fará para os fiéis após o juízo final.

22 Pilantra é o mesmo que desonesto.

${ }^{23}$ Pessoas vinculadas ao crime organizado.
} 


\section{A DEPENDÊNCIA SOCIAL}

O termo "dependência" é reconhecidamente vago e impreciso. Não à toa foi retirado do Manual diagnóstico estatístico de transtornos mentais (DSM) na sua quinta e última versão; porém, é amplamente usado e nada indica que irá desaparecer do discurso habitual dos técnicos e demais profissionais que trabalham com usuários de crack (SILVA OLIVEIRA, et al., 2017). Quando abordam o tema da dependência, referem-se geralmente à dependência química, apesar de haver uma tendência de procurar unir, ao menos no discurso, as dimensões biológica, psicológica e social. Mesmo assim, esta última é geralmente deixada de lado. Interessa ressaltar, dentro da definição de dependência química, o impulso a utilizar a substância de modo contínuo ou periódico. Esse impulso, por outros chamado de compulsão, seria o dado propriamente psicológico da dependência segundo o discurso estabelecido a respeito da dependência de substância. Muito embora, a produção acadêmica em psicologia vá além do modelo individualista ligado à ideia de compulsão, o que pode ser verificado, por exemplo, nos trabalhos contidos em Ronzani (2013). A dependência teria um aspecto físico e outro psicológico. O contexto social ficaria restrito, por exemplo, aos itens $\mathrm{V}$ e VI da DSM-IV, como o tempo "gasto em atividades necessárias para obtenção da substância" e na "utilização da substância ou na recuperação de seus efeitos", assim como no fato de que também "importantes atividades sociais, ocupacionais ou recreativas são abandonadas ou reduzidas devido ao uso de substâncias". (KAY; TASMAN; LIEBERMAN, 2002, p. 190)

Portanto, o contexto social é relegado pela DSM-IV às atividades de obtenção, uso e "recuperação" dos efeitos da droga. Contudo, o ritual de uso e as relações estabelecidas (até de companheirismo) entre os usuários são fundamentais para compreender a atração exercida pelo contexto social sobre os usuários de crack. Esse contexto também é atraente por fornecer um meio seguro para se usar a droga e se evitar as sanções das pessoas que são importantes para os usuários de crack. É um local de pessoas com interesses em comum em torno da droga, com uma visão, se não positiva, ao menos tolerante e dotada de valores com os quais se podem identificar e obter a satisfação negadas pela sociedade abrangente.

São definidos e desqualificados pelo uso de certa substância sem dominar sua produção, seu preço, sua qualidade, sua quantidade e sua disponibilidade. No 
entanto, a suposta perda da vontade é imposta de fora para dentro e não o inverso. Não é o usuário sob efeito do crack, sem domínio de seus desejos e atos, mas sim o "noia" socialmente construído (FRÚGOLI, e SPAGGIARI, 2010) e subsumido a um mercado e a uma legislação alheia à sua vontade.

Apesar de alienados das condições de produção e comercialização das substâncias, os usuários não perderam o domínio sobre sua vontade. Eles a usam diariamente em suas "correrias". O que thes foi negado são os meios de satisfação da necessidade de obter e usar a droga de uma forma diferenciada da impingida pelo mercado desregulamentado a partir do Estado: o tráfico. O usuário não perdeu o controle sobre sua existência, sobre sua capacidade de fazer escolhas e sobre sua independência. Em realidade, ele nunca as teve como usuário. Foi-lhe sempre vedado possuí-las, seja pelo mercado ou tráfico, seja pelo Estado. Enfim, como afirmam Bucher e Oliveira (1994), por toda máfia antidrogas. O morto vivo, o zumbi, qualquer segmento dessa maneira caracterizado, tornam-se alvos de políticas de higienização puramente repressivas.

Seguindo esse raciocínio, talvez então seja mais apropriado entender as cracolândias não como locais de zumbis mortos vivos, mas, ao contrário, como espaços de fuga do abandono, da quebra de vínculos pessoais, da desconexão. Por mais paradoxal que pareça, as cracolândias surgem como busca pela vida; não qualquer vida, mas a proporcionada pelo acolhimento em agrupamentos nos quais podem consumir crack sem ser julgados. Isso proporciona relativa segurança, pois a grande maioria das pessoas se considera "parças" umas das outras. Nesse campo de possibilidades, talvez a razão do crescente número de cracolândias e da atração para os usuários de crack vá muito além das substâncias. As cracolândias emanam uma força de atração; sob seu raio de ação, encontram-se os usuários de crack.

Ainda após anos sem utilizar a droga, reminiscências muito vagas podem voltar como nítidas recordações, mesmo quando em presença de usuários de crack diferentes daqueles com quem estava acostumado a usar a droga. A "biqueira" pode ser um local de imensa densidade social, onde assuntos relativos aos mais diversos aspectos da vida são ardorosamente discutidos pelos animados frequentadores. Casos exemplares são relembrados juntamente com os atores que deles participam. Tudo isso ajuda a compor uma memória sempre à disposição. Quando decidir para lá regressar, se verá novamente na presença dos componentes fundamentais da 
cultura do crack (ritual, parafernália de uso, valores, termos), que, embora não se encontrando de modo idêntico, servirão sempre de referências para comparação.

Voltar é sempre uma oportunidade para aquele que, mesmo inadvertidamente, se considere um ex-usuário possa verificar o lugar que ocupa no pensamento dos outros. Deixar de usar drogas, de viver a vida sob condições junkies (BURROUGHS, 2013 [1961]) é esquecer pessoas e lugares; concomitantemente, é ser esquecido por essas pessoas nesses lugares e ter consciência disso. Ser esquecido e esquecer é perceber certo dia, dentro de si, a morte daqueles de quem se olvidou e imaginar que também deve ter morrido no interior deles (CARUSO, 1989 [1968]).

Lembrar as atividades, as pessoas e os lugares onde se usou crack é retornar a um determinado ponto de vista entre os muitos possíveis na cidade. Os usuários de crack que habitam o centro de São Paulo, como é o caso dos meus interlocutores, possuem um determinado ângulo de observação da cidade e da vida nela. Mesmo após certo tempo longe das práticas, dos locais e das pessoas relacionadas ao uso de crack, sentem as mesmas sensações de antes: mal-estares pela presença policial, ou mesmo a fissura, ressurgem pela lembrança. Ainda que apartado do "fluxo", o ex-usuário continua recebendo sua influência.

Rodolphe Ingold (1983), membro da equipe médico-social do Hospital Marmottan, dirigido pelo pioneiro Claude Olivenstein, abordou no famoso Seminário de Marmottan, no início da década de 1980, o que ele nomeia como "efeito de dependência", já levando em conta uma mudança perene nos usuários de droga. Sua visão de mundo e a imagem construída pelos outros serão radicalmente alteradas. Além disso, sempre terão algo a ver com a droga, que passa a se incluir nas suas possibilidades de êxtase e de sofrimento. $\mathrm{Na}$ etnografia percebi que algo ocorrera a meus interlocutores: uma verdadeira transformação. Já não eram mais os mesmos de antes de fumar crack e não voltariam a sê-lo. A droga alargou/modificou irreversivelmente seu rol de possibilidades, colocando-os sob a ação do campo de forças do "fluxo".

Os materiais mais variados presentes no "fluxo" são introduzidos em uma corrente de transformações em que são combinados, adaptados e transformados, como se o cachimbo, por exemplo, fosse composto por uma matéria-fluxo que obriga o usuário de crack a estar sempre atento a impedir que ele se desfaça quando repetidamente em contato com um corpo posto em mutação pela ação da 
fumaça proveniente da pedra. O usuário e seu cachimbo são como o jardineiro e seu jardim. Quem cultiva está sempre atento para que o mato não tome conta do terreno. Enfim, lida o tempo todo com o caos, com a vida que se recusa a ser contida (INGOLD, 2015 [2011]).

Vida é movimento, e movimento é um valor compartilhado pelos frequentadores do "fluxo". Para que o maior número de pessoas possa atender seu desejo de fumar crack, o "bloco" 24 e suas frações devem se encontrar em circulação. O "fluxo" na Cracolândia não permanece em local fixo por muito tempo, ele também está sob o imperativo do deslocamento. Atrai os usuários que creem haver em seu interior blocos maiores. Mesmo o trabalho policial que, antes do DBA, se propunha a deslocar as pessoas e a empurrá-las de um lugar para outro, não estava em desacordo com os valores locais que privilegiavam a agitação do "corre" e do "fluxo" em contraponto ao sedentarismo do "parasita".

\section{CONSIDERAÇÕES FINAIS}

Após analisarmos os resultados de nossa etnografia, frente à bibliografia que consideramos apropriada ao tema, podemos extrair certas deduções a respeito: 1) de nossa discussão sobre o porquê da existência de grandes cenas abertas de uso de crack e da cracolândia paulistana em especial; 2) de como a ideia de dependência, para poder dar conta da atração exercida por estes territórios psicotrópicos, deve incorporar o contexto social de uso da droga.

Para começarmos a dar os primeiros contornos dos componentes sociais presentes na manutenção do uso do crack falamos a respeito da conexão com os pares nos locais de consumo da droga. Que permite, através do ingresso no "fluxo", compartilhar de certo modo de perceber e viver na cidade. Uma vez inserido no setting pode-se ter acesso perene à droga, aos objetos que compõe a parafernália, e mesmo aos meios de aquisição através da "treta". Caso se deseje afastar da cena de uso e prosseguir consumindo crack seria necessário dominar os sintomas associados para não comprometer as interações com outsiders, principalmente aqueles cuja opinião é valorizada, possuir fonte de fornecimento da droga e conseguir ter prazer em usá-la fora da presença dos "parças" e na proximidade de

\footnotetext{
${ }^{24} \mathrm{O}$ mesmo que pedra de crack
} 
não usuários. Além disso, neste convívio se tem acesso a uma visão alternativa e, por vezes, mesmo positiva a seu próprio respeito como pessoa e dotada de valores com os quais se pode identificar e obter a satisfação negada pela sociedade abrangente.

Ao contrário do convívio com outsiders as cracolândias proporcionam acolhimento em agrupamentos nos quais se pode consumir crack sem ser julgado. Isto atrai e permanece na memória: os "parças", o modo de vida, e as possibilidades de êxtase e sofrimento. Uma verdadeira transformação que alarga irreversivelmente o rol de possibilidades de convivência abertas pelo "fluxo"; e que corresponde ao caráter social da dependência. 


\section{REFERÊNCIAS}

ADERALDO, G.; FAZZIONI, N. Choro e samba na Luz: etnografia de práticas de lazer e trabalho na R. Gal. Osório, Ponto Urbe [Online], 11 | 2012, posto online no dia 01 Dezembro 2012, consultado 03 Março 2017. URL:

http://pontourbe.revues.org/1159 DOI: 10.4000/pontourbe.1159

ADORNO, R. C. F., et al.. "Etnografia da cracolândia: notas sobre uma pesquisa em território urbano" [Ethnography of Crackland: notes about a research in urban territory], Saúde \& Transformação Social/Health \& Social Change, 4 (2), 04-13, 2013.

ADORNO, R. C. F. , et al. "Amarga delícia: experiências de consumo de crack na região central de São Paulo (BR)”. Revista Inter-Legere, (15), 87-109, 2014.

ALVES, Y. "A Cracolândia como "Communitas" e o frade craqueiro", em T. Ramminger, e M. Silva, orgs., Mais substâncias para o trabalho em saúde com usuários de drogas. Porto Alegre, Rede Unida, 83-98, 2015.

ALVES, Y. Jamais fomos zumbis: contexto social e craqueiros na cidade de São Paulo. Salvador: Ed. UFBA, 2017.

ARAÚJO, R. B., et al. "Craving e dependência química: conceito, avaliação e tratamento", Jornal Brasileiro de Psiquiatria, 57(1), 57-63, 2008.

BECKER, H. S. Outsiders: estudos de sociologia do desvio, Rio de Janeiro, Jorge Zahar, 2008 [1963].

BOURGOIS, P.;SCHONBERG, J. Righteous dopefiends. Los Angeles: University of California Press, 2009.

BUCHER, R.; OLIVEIRA, S. O discurso do "combate às drogas" e suas ideologias. Rev. Saúde Pública, v.28, n.2, p. 137-45.abr.1994.

BURROUGHS, W. Junky. São Paulo, Companhia da Letras, 2013 [1961].

CALIL, T. G. "Relatos e imagens da cracolândia: modos de vida e resistência na rua", Cadernos de Arte e Antropologia, 5(2), 91-102, 2016.

CARUSO, I. A.; TREVISAN, J. S. A separação dos amantes: uma fenomenologia da morte. São Paulo, Cortez, 1989. 
CHAGAS, Arnaldo Toni; SEEGER, Fabiano Dutra. Crack na mídia impressa: um estudo sobre a produção de sentido no discurso jornalístico sobre o crack. Barbarói - revista do Departamento de Ciências Humanas e do Departamento de Psicologia, v. 19, n. 38, 2013, p. 145-177.

CHAVES, T. V., et al. "Crack cocaine craving: behaviors and coping strategies among current and former users". Revista de Saúde Pública, 45(6), 1168-1175, 2011.

COELHO, I., e M. H. B. D. Oliveira. "Internação compulsória e crack: um desserviço à saúde pública", Saúde em Debate, 38(101), 359-367, 2014.

COSTA, T. G. C. D. Condições do lugar: relações entre saúde e ambiente para pessoas que usam crack no bairro da Luz, especificamente na região denominada cracolândia. São Paulo, Universidade de São Paulo, tese de doutorado, 2015.

FERES JÚNIOR, J. O. "Crack na Grande Mídia", em Moreira M.R., J. M. Ribeiro, e F.M.B. Fernandes, orgs., A Saúde do Adolescente e do Jovem e suas Interfaces com a Saúde Mental: estudo sobre a questão do Crack - Relatório de Pesquisa. Rio de Janeiro, Fiocruz, 2012.

FERNANDES, Luís; Pinto, Marta. El espacio urbano como dispositivo de control social: territorios psicotrópicos y políticas de la ciudad. Monografías humanitas, v. 5, p. 147-162, 2004.

FIORE, M. Uso de drogas: substâncias, sujeitos e eventos. Tese (Doutorado) Universidade Estadual de Campinas, Instituto de Filosofia e Ciências Humanas,Campinas, SP, 2013.

FRÚGOLI JÚNIOR, H.; SPAGGIARI, E. "Da cracolândia aos nóias: percursos etnográficos no bairro da Luz". Ponto Urbe: Revista do Núcleo de Antropologia Urbana da USP, 6, 2010.

FRÚGOLI JÚNIOR, H.; CAVALCANTI, M. "Territorialidades da(s) cracolândia(s) em São Paulo e no Rio de Janeiro”, Anuário Antropológico, (II), 73-97, 2013.

GOFFMAN, E. Estigma: notas sobre a manipulação da identidade deteriorada. 4 ed. Rio de Janeiro, Guanabara Koogan,1975 [1963]. 
INGOLD, R. "O estado de dependência", em C. Olivenstein. A vida do toxicômano, Rio de Janeiro, Zahar, 1983 [1982].

JOANIDES, H. M. Boca do Lixo. 5.ed. São Paulo: Populares, 1978.

JORGE, M. S. B., et al. "Ritual de consumo do crack: aspectos socioantropológicos e repercussões para a saúde dos usuários". Ciência \& Saúde Coletiva, 18(10), 29092918, 2013. https://dx.doi.org/10.1590/S1413-81232013001000015

KAY, J.;TASMAN, A.; LIEBERMAN, J. A. Psiquiatria: ciência comportamental e fundamentos clínicos. Barueri: Manole, 2002.

LEARY, T. Flashbacks "surfando no caos": a história pessoal e cultural de uma era - Uma autobiografia. São Paulo, Beca Produções Culturais, 1999 [1990].

LEMÕES, Tiago. De vidas infames à máquina de guerra: etnografia de uma luta por direitos. 2017. 298 p. Tese (Doutorado em Antropologia Social) - Programa de Pós-Graduação em Antropologia Social, Universidade Federal do Rio Grande do Sul, Porto Alegre, 2017.

MALHEIROS, L. "Tornando-se um usuário de crack". In: A. Nery Filho. et al em As drogas na contemporaneidade: perspectivas clínicas e culturais. Salvador, EDUFBA, 79-100, 2012.

MALHEIROS, L. "Entre sacizeiro, usuário e patrão: um estudo etnográfico sobre consumidores de crack no centro Histórico de Salvador", em E. Macrae, R. L. Tavares, M. E. Nuñes, orgs., Crack: contextos, padrões e propósitos de uso, Salvador, EDUFBA, 154-227, 2013.

MERCANTE, M. Imagens de cura: Ayahuasca, imaginação, saúde e doença na Barquinha. Rio de Janeiro: Editora FIOCRUZ, 2015.

MOURA, Y. G. D.; Silva, E. A. D.; Noto, A. R. "Redes sociais no contexto de uso de drogas entre crianças e adolescentes em situação de rua", Psicologia em

Pesquisa, 3(1), 31-46, 2009.

NEWMAN, A. K. A study of the causes leading to the extinction of the Maori. Trans. N.-Zel. Inst., XIV, 459-477, 1882. Disponível em:

http://rsnz.natlib.govt.nz/volume/rsnz 14/rsnz 1400 006550.pdf 
OLIVEIRA, L. G. D., e S. A. Nappo. "Caracterização da cultura de crack na cidade de São Paulo: padrão de uso controlado”. Revista de Saúde Pública, 42(4), 664-671, 2008.

ORTIZ, E. Por que não dancei, São Paulo, Senac, 2001.

PINHEIRO, D., e J. S. Anjos, 2014, "Paraísos artificiais: alteridades e práticas urbanas". Revista Espaço Acadêmico, 14 (163), 43-49.

PREFEITURA DO MUNICÍPIO DE SÃO PAULO. "Programa de Braços Abertos completa um ano com diminuição do fluxo de usuários e da criminalidade na região", Transparência São Paulo, 2015. Recuperado em: 30 jan. 2017, de http://capital.sp.gov.br/noticia/programa-de-bracos-abertos-completa-um-ano-com

RAUP, L. M., e R. D. C. F. Adorno. “Jovens em situação de rua e usos de crack: um estudo etnográfico em duas cidades”. Revista Brasileira de Adolescência e Conflitualidade, (4):52-67, 2015.

ROMANINI, M., e A. Roso. "Midiatização do crack e estigmatização: corpos habitados por histórias e cicatrizes". Interface: Comunicação, Saúde, Educação, 18(49), 363-376, 2014.

RONZANI, T. M. Ações integradas sobre drogas: prevenção, abordagens e políticas públicas. Juiz de Fora: Ed. UFJF, 2013. 448 p.

RUI, T. "Depois da Operação Sufoco: sobre espetáculo policial, cobertura midiática e direitos na Cracolândia paulistana". Revista Semestral do Departamento e do Programa de Pós-Graduação em Sociologia da UFSCar, 3(2), 287, 2013.

RUI, T. "Vigiar e cuidar: notas sobre a atuação estatal na 'cracolândia'”. Revista Brasileira de Segurança Pública, São Paulo, 6 (2), 336-351, 2012.

RUI, T. "Usos da Luz e da cracolândia: etnografia de práticas espaciais". Saúde e Sociedade, 23(1), 91-104, 2014.

RUI, T. Nas tramas do crack: etnografia da abjeção. Editora Terceiro Nome, 2018.

SILVA OLIVEIRA, M., et al. "Sintomas internalizantes e externalizantes em usuários de cocaína-crack”, Psychologica, 59(1), 43-53, 2017. 
SILVA, S. L.; ADORNO, R. C. F. "A etnografia e o trânsito das vulnerabilidades em territórios de resistências, registros, narrativas e reflexões a partir da Cracolândia" [Ethnography and vulnerabilities shifts in resistance territories: registers, narratives and thoughts from Cracolândia]. Saúde \& Transformação Social/Health \& Social Change, 4(2), 21-31, 2013.

SPAGGIARI, E., W. E. Rodrigues, W. E., e I. Z. D. Fonseca. «Etnografia da atuação de entidades sociais na região da Luz », Ponto Urbe [Online], 11 | posto online em 1 dez 2012, consultado em 3 mar 2017. URL :

http://pontourbe.revues.org/1143; DOI : 10.4000/pontourbe.1143

TINOCO, R. "Notas sobre a contrução psico-social da identidade desviante em toxicodependência", Toxicodependências, 5, 11-23, 1999.

VELHO, G. "Estudo do comportamento desviante: a contribuição da antropologia social". In: G. Velho, Um antropólogo na cidade: ensaios de antropologia urbana. Rio de Janeiro, Zahar, 36-51, 2013.(Antropologia Social). 